\title{
Moving from Norms Rhetorics to Norms Empirics: A Rejoinder to ,Local Gender Norms: Persistence or Change?' by Clara Neupert-Wentz
}

\author{
Mario Krauser • Gerald Schneider · Tim Wegenast
}

Published online: 28 April 2020

(C) The Author(s) 2020

We have recently established together with Ingeborg Hess Elgersma that different ownership arrangements in the extractive industry affect gender equality in contrasting ways (Krauser et al. 2019). While international investment in the mining industry lowers female labor market integration, it also reduces the risk of intimate partner violence. These results add to the proposition of our earlier studies that the resource curse literature needs to consider the micro-management of the extractive industry (e.g. Wegenast and Schneider 2017; Wegenast et al. 2018).

In an interesting contribution, Neupert-Wentz (2020) criticizes our recent article in this journal for largely disregarding the role of traditional gender roles and for thus insufficiently contextualizing the effects that the extractive industry has on the labor market integration of females and intimate partner violence in Sub-Sahara Africa. The main gist of her argument is that the effect of an intervention might depend on local norms: "The types of local gender norms can have varying effects on gender equality. For instance, there could be considerable differences between inheritance norms, marriage customs, and traditional harmful practices, such as female genital cutting" (Neupert-Wentz 2020). In addition, she claims that different types of interventions might have different effects on gender equality.

As we have never argued that investment in the extractive industry affects gender equality or other social outcomes in a comparable way to wars, natural catastrophes

\footnotetext{
M. Krauser $\cdot$ G. Schneider $(\bowtie) \cdot$ T. Wegenast International Relations Chair, Department of Politics and Public Administration and Cluster of Excellence "The Politics of Inequality", Universität Konstanz, Box 86, 78457 Konstanz, Germany E-Mail: Gerald.Schneider@uni-konstanz.de

M. Krauser

E-Mail: mario.2.krauser@uni-konstanz.de

T. Wegenast

E-Mail: tim.wegenast@uni-konstanz.de
} 
Fig. 1 Polygyny in Districts with Various Number of Mines

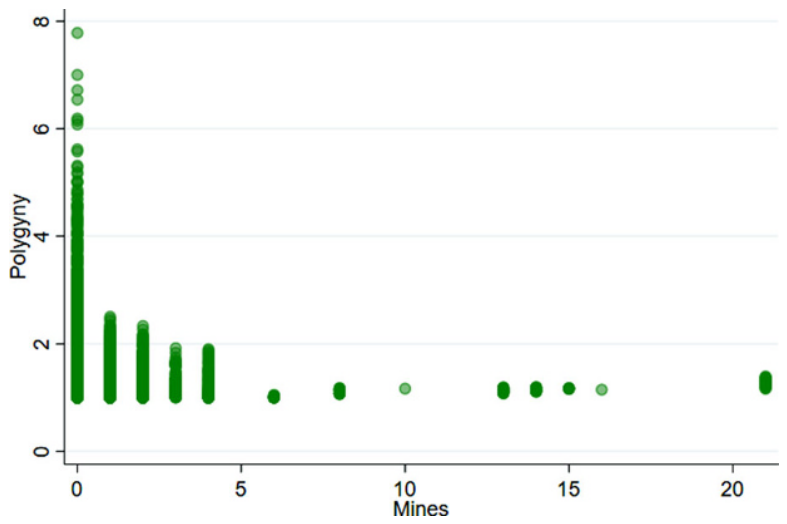

or other "interventions", we fully agree with Neupert-Wentz' second remark. We take, however, issue with her first claim. Her reply neither elucidates theoretically, nor demonstrates empirically, how long-lasting local gender norms could affect the impact of investments in the resource sector. Given the author's previous research on local norms (Koos and Neupert-Wentz 2020), we were surprised to be confronted with a reply void of any evidence in support of alternative causal mechanisms than the ones developed by us.

Table 1 Effect of International Mineral Control Rights on Polygyny per District, using DHS-Data

\begin{tabular}{lll}
\hline & $(3)$ & $(4)$ \\
VARIABLES & Polygyny & Polygyny \\
\hline Domestic mines & -0.0339 & -0.00143 \\
& $(0.0296)$ & $(0.0343)$ \\
International mines & -0.0188 & -0.00497 \\
Skilled labor & $(0.0128)$ & $(0.0163)$ \\
& & -0.137 \\
Higher education & & $(0.0875)$ \\
& & $-0.355^{* * *}$ \\
Wealth & & $(0.0815)$ \\
& & $-2.82 \mathrm{e}-09$ \\
Electricity & & $(3.20 \mathrm{e}-08)$ \\
& & $-0.0848^{* * *}$ \\
Constant & & $(0.0299)$ \\
& $1.379^{* * *}$ & $1.369^{* * *}$ \\
Observations & $(0.000484)$ & $(0.0101)$ \\
R-squared & 25,587 & 11,061 \\
Number of Districts & 0.000 & 0.033 \\
\hline
\end{tabular}

NOTE: Linear regressions with district-fixed effects and number of wives per married husband as dependent variable. Standard errors in parentheses

$* * * p<0.01, * * p<0.05, * p<0.1$ 
Table 2 Interacted Effect of Polygyny and Mineral Control Rights on Female Unemployment per District, using DHS-Data

\begin{tabular}{lll}
\hline & $(1)$ & $(2)$ \\
VARIABLES & Unemployed female & Unemployed female \\
\hline Domestic mines & $-0.486^{* * *}$ & $-0.292^{* *}$ \\
& $(0.115)$ & $(0.126)$ \\
International mines & $1.213^{* * *}$ & $1.349^{* * *}$ \\
& $(0.117)$ & $(0.189)$ \\
Polygyny & $-0.254^{* * *}$ & $-0.213^{* * *}$ \\
& $(0.0458)$ & $(0.0540)$ \\
International mines* & $-0.884^{* * *}$ & $-1.118^{* * *}$ \\
Polygyny & $(0.0986)$ & $(0.166)$ \\
Skilled labor & & $-2.488^{* * *}$ \\
& & $(0.194)$ \\
Higher education & & $-1.110^{* * *}$ \\
Joint spending decision & & $(0.185)$ \\
& & -0.0878 \\
Wealth & & $(0.0575)$ \\
& & $0.0870^{* * *}$ \\
Constant & & $(0.0182)$ \\
Observations & & $-0.193^{* *}$ \\
\hline
\end{tabular}

NOTE: Fractional pooled logistic regressions with district-fixed effects and unemployment rate as dependent variable. Robust standard errors in parentheses

$* * * p<0.01, * * p<0.05, * p<0.1$

To explore the possible role of traditional gender norms for the resource curse, we have conducted some empirical tests that resort to the key explanatory variable used in Neupert-Wentz's previous research-polygyny. We measure this concept in line with Koos and Neupert-Wentz (2020) at the local level. To gather this information, we draw on the same DHS-data and methodology as in our original study (Krauser et al. 2019) and employ variable v505 to compute for each district the average number of wives per married men-with values above one reflecting polygyny. ${ }^{1}$ Fig. 1 depicts the values of both variables in our dataset. Prima facie, we note the limited extent of polygyny in mining districts.

Table 1 examines whether the presence of the extractive sector influences the persistence of traditional gender norms. It shows that mining does not alter traditional local gender norms. Ownership in the mining sector, be it through international or domestic investors, does not affect polygyny in a significant way in either model. This supports Neupert-Wertz's (2020) claim that gender norms persist in the long term and are not easily altered through significant economic changes.

This important result does, however, not invalidate our finding that international ownership in the mining industry increases women's overall unemployment, shifts

\footnotetext{
1 The variable asks women about their husbands' number of other wives.
} 

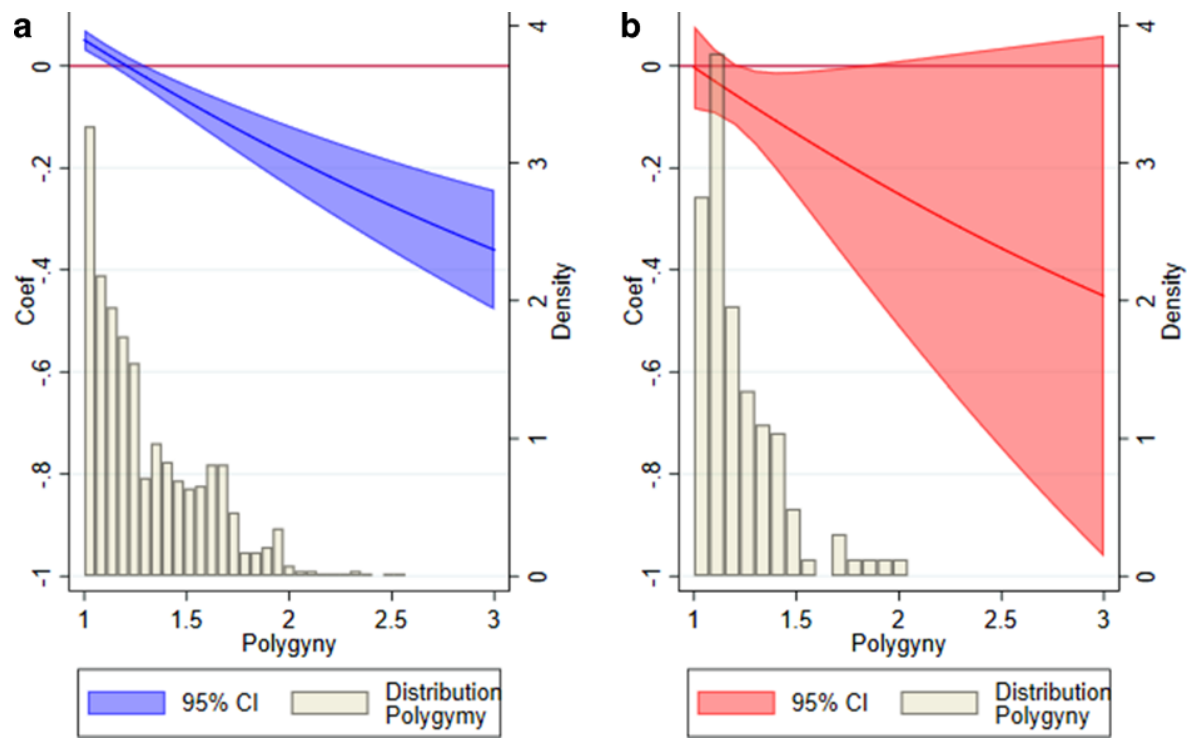

Fig. 2 Marginal Effects of Mine Ownership and Polygyny on Female Unemployment. a International Mines. b Domestic Mines

female sectoral occupation from agriculture to the service sector and lowers domestic violence. On the contrary, we find that our earlier results always survive both in terms of direction and significance when we interact Polygyny with our key explanatory variable International mines. Thus, our core results do not come about because they coincide with tenacious gender norms, but precisely because they support a theoretical mechanism that operates outside the realm of the social practices that Neupert-Wentz describes as the main, if not sole driver of gender inequality. Tables 2 and 3 provide evidence in line with our argument that ownership arrangements in the extractive industry affect local labor markets.

Table 2 scrutinizes the combined effects of international mines and polygyny on women's labor market integration. We find that the interacted coefficient indeed changes course compared to the sustained positive individual effect of international mines. Districts featuring marriage norms marginalizing women as well as more pronounced international mining exhibit lower female unemployment.

Fig. 2 plots the conditional effects at different values of polygyny. It illustrates that the impact of international mining remains positive until approximately 1.4 wives per husband-which make up the majority of the sample. We furthermore compare this to the corresponding results of domestic mines and find no significant effect among the most prevalent values of polygyny. ${ }^{2}$ The results simply suggest that the one local gender norm examined here does not have to do as much with mining as suggested by Neupert-Wentz (2020).

\footnotetext{
2 This estimation mirrors the strategy used in Table 2, Model 2, but exchanges the interaction term to Domestic mines* Polygyny.
} 
Table 3 Interacted Effect of Polygyny and Mineral Control Rights on Female Sectoral Occupation per District, using DHS-Data

\begin{tabular}{lllll}
\hline & $(1)$ & $(2)$ & $(3)$ & $(4)$ \\
VARIABLES & Agriculture & Agriculture & Services & Services \\
\hline Domestic mines & -0.158 & -0.0572 & $-0.367^{* * *}$ & 0.170 \\
& $(0.116)$ & $(0.166)$ & $(0.104)$ & $(0.134)$ \\
International mines & $-2.252^{* * *}$ & $-2.062^{* * *}$ & $0.520^{*}$ & $1.268^{* * *}$ \\
& $(0.245)$ & $(0.277)$ & $(0.287)$ & $(0.373)$ \\
Polygyny & $0.634 * * *$ & 0.117 & $-0.967 * * *$ & $-0.586^{* * *}$ \\
& $(0.0643)$ & $(0.0721)$ & $(0.0642)$ & $(0.0700)$ \\
International mines* & $1.512^{* * *}$ & $1.298^{* * *}$ & -0.351 & $-0.808^{* *}$ \\
Polygyny & $(0.199)$ & $(0.201)$ & $(0.238)$ & $(0.317)$ \\
Higher education & & $-4.472^{* * *}$ & & $0.980^{* * *}$ \\
& & $(0.678)$ & & $(0.309)$ \\
Skilled labor & & $-4.557 * * *$ & & $-2.067 * * *$ \\
& & $(0.453)$ & & $(0.372)$ \\
Wealth & & $-1.18 \mathrm{e}-06^{* * *}$ & & $-1.04 \mathrm{e}-06^{* * * *}$ \\
Electricity & & $(2.23 \mathrm{e}-07)$ & & $(2.70 \mathrm{e}-07)$ \\
Constant & & $-0.517 * * *$ & & $0.784^{* * *}$ \\
& & $(0.184)$ & & $(0.121)$ \\
Observations & & $-0.480^{* * *}$ & $-1.885^{* * *}$ & $-2.323^{* * *}$ \\
\hline
\end{tabular}

NOTE: Fractional pooled logistic regressions with district-fixed effects and share of women working in agricultural and service sectors as dependent variable. Robust standard errors in parentheses $* * * p<0.01, * * p<0.05, * p<0.1$

Moreover, though empirically interesting, the regularity established so far does not easily lend itself to the development of policies through which local communities could escape the gendered resource curse of the inhibiting social norms. In other words, norms that disadvantage women are not safeguards against another harm-foreign firms that diminish their ability to maintain an independent income. As the effect mediated by polygyny is the same as its solitary contribution, we doubt that its sheltering role yields leverage for gender equality.

In Table 3 we analyze how international mining and polygyny affect the sectoral occupation of women. Akin to Table 2, we detect that the preserving effect of local marriage norms dominates the impact that foreign mineral extraction has on sectoral female employment. Women's participation in agricultural work is more pronounced in districts that are both more polygynous and host more international mines.

Furthermore, women are less represented in the service sector under these conditions. Again, as polygyny dominates the interacted effect, we wish to caution against attempts that seek to derive clear theoretical insights from this result.

Lastly in Table 4, we test in line with our original article the interacted effect of international mines and polygyny on domestic violence. It reveals that the combined effect of international mining and polygyny increases the share of women experienc- 
Table 4 Interacted Effect of Polygyny and Mineral Control Rights on Women per District being punched, using DHS-Data

\begin{tabular}{|c|c|c|}
\hline & (1) & (2) \\
\hline VARIABLES & Punched & Punched \\
\hline \multirow[t]{2}{*}{ Domestic mines } & -0.180 & -0.0872 \\
\hline & $(0.120)$ & $(0.180)$ \\
\hline \multirow[t]{2}{*}{ International mines } & $-1.236 * * *$ & $-0.749 * * *$ \\
\hline & $(0.206)$ & $(0.220)$ \\
\hline \multirow[t]{2}{*}{ Wives } & $0.176^{* *}$ & $0.249 * * *$ \\
\hline & $(0.0767)$ & $(0.0901)$ \\
\hline \multirow[t]{2}{*}{ International mines*wives } & $0.927 * * *$ & $0.401 * *$ \\
\hline & $(0.160)$ & $(0.204)$ \\
\hline \multirow[t]{2}{*}{ Higher education } & & $-2.039 * * *$ \\
\hline & & $(0.361)$ \\
\hline \multirow[t]{2}{*}{ Wealth } & & $-5.72 \mathrm{e}-05$ \\
\hline & & $(0.0497)$ \\
\hline \multirow[t]{2}{*}{ Joint spending decision } & & $-0.747 * * *$ \\
\hline & & $(0.173)$ \\
\hline \multirow[t]{2}{*}{ Muslim } & & $0.272 * * *$ \\
\hline & & $(0.104)$ \\
\hline \multirow[t]{2}{*}{ Christian } & & 0.0912 \\
\hline & & $(0.134)$ \\
\hline \multirow[t]{2}{*}{ Constant } & $-1.473 * * *$ & $-2.947 * * *$ \\
\hline & $(0.0695)$ & $(0.173)$ \\
\hline Observations & 18,401 & 6491 \\
\hline
\end{tabular}

NOTE: Fractional pooled logistic regressions with district-fixed effects and share of women being punched as dependent variable. Robust standard errors in parentheses

$* * * p<0.01, * * p<0.05, * p<0.1$

ing physical abuse, while international investment in isolation reduces interpersonal violence.

Again, plotting the conditional effects in Fig. 3, we find the negative effect of international mines holds throughout the most common values of polygyny in our sample. ${ }^{3}$ The double result confirms that our original estimation remains robust and that the disruptive change that the mining industry brings to a region is not sufficient in overturning the high risk for females of experiencing intimate partner violence in regions dominated by traditional gender norms such as polygyny.

We want to conclude by stressing that Neupert-Wertz (2020) correctly suspects that long-term local gender norms survive the structural shift in the labor market and act in this sense as a mediating variable that has been overlooked so far in studies of what we have called the "gendered resource curse" (Krauser et al. 2019). Recent research credibly demonstrates why it is important to take time seriously

\footnotetext{
3 The interacted effect of domestic mines, in turn, is not significant within this range (estimations based on the strategy used in Table 4, Model 2, and an interaction term converted to Domestic mines*Polygyny).
} 
a

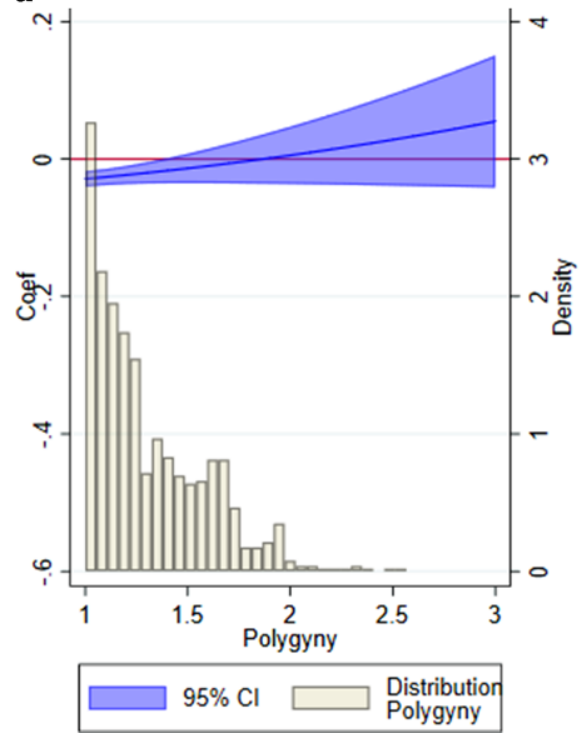

b

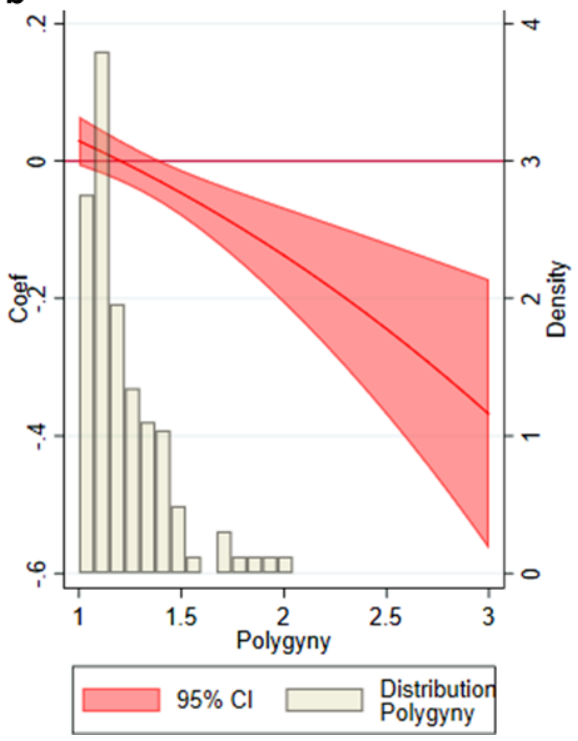

Fig. 3 Marginal Effects of Mine Ownership and Polygyny on Domestic Violence. a International Mines. b Domestic Mines

when assessing the socio-economic impacts of extractive industries (Orihuela and Gamarra-Echenique 2020).

We nevertheless believe that the added theoretical value of research on longlasting gender roles is limited and that it shields the development community with fatalistic conclusions against the designing of policy measures that improve the role of females in fragile contexts. It is theoretically unsurprising that the recent advancement of the mining industry in sub-Sahara Africa leaves long-lasting unequal gender norms intact—otherwise these would not be long-lasting in the first place. We also welcome more explicit expectations about the triangular relationship relating to natural resource management. These could go beyond merely highlighting the potential for backfiring in cases where norms are incongruent with empowerment efforts in substantially distinct development contexts. A disproportional focus on this structural connection nevertheless clouds the dynamic aspects of the resource-gender relationship that is increasingly addressed in the international policy arena. Only present-day policy changes might help us to fight social ills as gender inequality, underdevelopment, or violence that we have theoretical and empirically traced back to ownership arrangements, knowing of course that this is not the only structural barrier working against women in the developing world.

Funding Open Access funding provided by Projekt DEAL.

Open Access This article is licensed under a Creative Commons Attribution 4.0 International License, which permits use, sharing, adaptation, distribution and reproduction in any medium or format, as long as you give appropriate credit to the original author(s) and the source, provide a link to the Creative Commons licence, and indicate if changes were made. The images or other third party material in this article 
are included in the article's Creative Commons licence, unless indicated otherwise in a credit line to the material. If material is not included in the article's Creative Commons licence and your intended use is not permitted by statutory regulation or exceeds the permitted use, you will need to obtain permission directly from the copyright holder. To view a copy of this licence, visit http://creativecommons.org/licenses/by/4.0/.

\section{References}

Koos, Carlo, and Clara Neupert-Wentz. 2020. Polygynous neighbors, excess men, and intergroup conflict in rural Africa. Journal of Conflict Resolution 64(2/3):402-431.

Krauser, Mario, Tim Wegenast, Gerald Schneider, and Ingeborg Hess Elgersma. 2019. A gendered resource curse? Mineral ownership, female unemployment and domestic violence in Sub-Saharan Africa. Zeitschrift für Friedens- und Konfliktforschung 8:213-237.

Neupert-Wentz, Clara. 2020. Local gender norms: persistence or change? Reply to "A gendered resource curse? Mineral ownership, female unemployment and domestic violence in sub-saharan africa" by Mario Krauser, Tim Wegenast, Gerald Schneider, and Ingeborg Elgersma. Zeitschrift für Friedensund Konfliktforschung. https://doi.org/10.1007/s42597-020-00026-0.

Orihuela, José Carlos, and Victor Gamarra-Echenique. 2020. Fading local effects: boom and bust evidence from a Peruvian gold mine. Environment and Development Economics 25(2):182-203.

Wegenast, Tim, and Gerald Schneider. 2017. Ownership matters: natural resources property rights and social conflict in Sub-Saharan Africa. Political Geography 61:110-122.

Wegenast, Tim, Arpita Khanna, and Gerald Schneider. 2018. The micro-foundations of the resource curse: oil ownership and local economic well-being in sub-saharan africa. GSDS working paper 2018-02. https://www.gsds.uni-konstanz.de/research/working-papers/. Accessed April 14, 2020 